\title{
LEÍSMO NO PERSONAL Y NEUTRO DE MATERIA
}

\author{
JAVIER GARCÍA MENÉNDEZ \\ Universidad de Oviedo
}

\author{
Al Prof. D. Francisco García González \\ In memoriam
}

En cuanto a las desviaciones de los pronombres átonos respecto del paradigma etimológico, el siglo XVI resulta clave. Lo es, en primer lugar, por tratarse de la etapa definitiva en la consumación del leísmo, finalmente concluida en el XVII. En segundo lugar, y como consecuencia de lo anterior, la expansión del pronombre $l e$ en el complemento directo ${ }^{1}$ de "persona», casi absoluta en la época, abre la puerta al leísmo no personal, ofreciendo la situación idónea para el afianzamiento de este fenómeno (§ 4.6.). Así, el siglo XVI constituye un período muy provechoso a la hora de evaluar el comportamiento de los referentes átonos de $\mathrm{CD}$, sobre todo en la vertiente del leísmo no personal. Tal desviación sobre la norma etimológica -el empleo de le como CD masculino de «no persona»- es lo que voy a estudiar en las siguientes páginas.

Antes de comenzar, se hace necesario advertir que solamente pretendo apuntar, de forma esquemática, los usos leístas que se producen en el campo de la «no persona» a lo largo del siglo XVI y, a partir de algunos aspectos que se desprenden de su análisis ${ }^{2}$, esbozar una hipótesis que, inte-

\footnotetext{
${ }^{1}$ En lo que sigue utilizaré la abreviatura CD para el complemento directo y CI para el indirecto.

${ }^{2}$ Aspectos que, en parte, conducen a conclusiones novedosas, debido al escaso interés que se le viene prestando a la oposición «continuo» / «discontinuo» en el uso de los pronombres átonos, si se exceptúan las aportaciones procedentes de la Dialectología y la Sociolingüística. Desde estas áreas se han ocupado del tema Francisco García González y Flora Klein-Andreu, cuyos trabajos más destacados cito a continuación como bibliografía esencial. De F. García González, «El leísmo en Santander», en Estudios ofrecidos a Emilio Alarcos Llorach, III, Oviedo, Universidad de Oviedo, 1978, págs. 87-101; «Los pronombres personales en el oriente de Asturias», en Estudios y trabayos del Seminariu de llingua asturiana, II, Oviedo, Universidad de Oviedo, 1979, págs. 47-56; «/le (lu), la, lo (lu)/ en el Centro-Norte de la Penín-
}

$R F E$, LXXX, $2000,1 .^{\circ}-2 .^{\circ}$, págs. $51-68$ 
grada en los planteamientos generales sobre el origen y evolución del leísmo castellano, considere un matiz que hasta ahora parece haber pasado desapercibido: la influencia subyacente del neutro de materia.

Las limitaciones del presente trabajo imponen un alto grado de prudencia. Por ello, la tesis que sostendré debe ser tomada como propuesta provisional, a la espera de otras investigaciones que confirmen su vigencia en textos antiguos y modernos, así como en la lengua oral de hoy en día.

\section{Datos generales: Frecuencia del Leísmo en los teXtos}

He manejado un corpus de 932 ejemplos correspondientes al uso de los referentes átonos le, les, lo, los en función de $\mathrm{CD}$ masculino. Los textos han sido revisados íntegramente con el fin de evitar recuentos parciales que propicien la observación de campos léxicos restringidos. La selección de las obras ha intentado reflejar la evolución lingüística del XVI, desde su inicio hasta su ocaso y entrada en el XVII, sin olvidar la etapa intermedia. Por tal causa la exploración se ha realizado sobre La Celestina de Rojas, el Lazarillo de Tormes y La gitanilla de Cervantes.

En lo relativo al método de estudio, la forma de examinar con fiabilidad los textos hubo de ser un cómputo numérico expresado en porcentajes. Sirva como aproximación a lo único que podemos medir: la frecuencia de uso.

Los datos generales que se registran son los siguientes.

En La Celestina:

a) $\mathrm{CD}$ masculino de «persona»: $92 \%$ le, $8 \%$ lo (singular); $5 \%$ les, $95 \%$ los (plural).

sula», Verba, 8, 1981, págs. 347-353; "Algo más sobre el neutro de materia», Lletres asturianes, 17, 1985, págs. 31-36; "El neutro de materia», en Homenaje a Alonso Zamora Vicente, II, Madrid, Castalia, 1989, págs. 91-105. De F. Klein-Andreu, «Factores sociales en algunas diferencias lingüísticas en Castilla la Vieja», Papers. Revista de Sociología, 11, 1979, págs. 45-64; «Distintos sistemas de empleo de le, la, lo. Perspectiva sincrónica, diacrónica y sociolingüística», Thesaurus, XXXVI, 1981, págs. 284-304, reproducido en Los pronombres átonos, ed. O. Fernández Soriano, Madrid, Taurus Universitaria, 1993, págs. 337-353 (cito por esta última edición); «Neuterality, or the Semantics of Gender in a Dialect of Castilla», en Proceedings of the IXth Linguistic Symposium on Romance Languages, ed. W. Cressey y D. J. Napoli, Washington, Georgetown University Press, 1981, págs. 164-176. Una perspectiva de conjunto, con amplia bibliografia, la ofrece Inés Fernández-Ordóñez, «Leísmo, laísmo y loísmo: estado de la cuestión», en Los pronombres átonos, págs. 63-96. .

${ }^{3}$ Cito por las siguientes ediciones: Fernando de Rojas, La Celestina, ed. Dorothy S. Severin, Madrid, Cátedra, 1991 (sigue como texto base el de Zaragoza, 1507); Lazarillo de Tormes, ed. Francisco Rico, Madrid, Cátedra, 1997 (utiliza la edición de Burgos, 1554); Miguel de Cervantes, Novela de la Gitanilla, en Novelas ejemplares I, ed. Harry Sieber, Madrid, Cátedra, 1995, págs. 59-134 (reproduce con fidelidad la príncipe de Juan de la Cuesta, Madrid, 1613). En las citas de ejemplos se refieren la obra y la página de donde han sido tomados. La clave de las letras es $C$ (Celestina), L (Lazarillo), G (Gitanilla). 
b) CD masculino de «no persona»: $42 \%$ le, $58 \%$ lo, los. No se utiliza les para el plural.

En el Lazarillo de Tormes:

a) $\mathrm{CD}$ masculino de «persona»: $90 \%$ le, $10 \%$ lo (singular); $10 \%$ les, $90 \%$ los (plural).

b) CD masculino de «no persona»: $29 \%$ le, $71 \%$ lo, los. No se usa les para el plural.

En La gitanilla:

a) CD masculino de «persona»: $100 \%$ le (no hay lo en singular), $100 \%$ los (no hay les en plural).

b) CD masculino de «no persona»: $66 \%$ le, $34 \%$ lo, los. No se emplea les en plural.

A la vista de las cifras cabe resaltar el hecho de que el leísmo de «persona» es dominante, pero sólo en singular; en plural se encuentra muy poco extendido (apenas alcanza el $10 \%$ de los casos). En cuanto al leísmo no personal, los porcentajes rondan el $30-40 \%$ en La Celestina y el Lazarillo, aumentando considerablemente en la prosa cervantina hasta ocupar dos tercios del total. Para lo que me interesa, es de capital importancia el que este tipo de leísmo únicamente se produzca en singular. En consecuencia, obviaré desde este momento toda mención al número «plural».

Pasemos ahora a examinar en profundidad el campo de la «no persona», ejemplificando sobre algunos pasajes escogidos.

\section{El CD masculino no PERSONAL EN EL SIGLO XVI}

2.1. En coexistencia con el rasgo «no persona», el género «masculino» y el número «singular», el uso de los pronombres átonos de CD presenta alternancia entre le y lo referidos a sustantivos cuyos contenidos léxicos se hallan muy próximos:

Saquen un cavallo; límpienle mucho; aprieten bien la cincha, por que si passare por casa de mi señora y mi Dios $(C, 136)$.

[...] uno piensa el vayo y otro el que $l o$ ensilla $(C, 320)$.

E incluso con un mismo sustantivo:

Y por que el incogitado dolor te dé más pena, todo junto sin pensarle, [...] vez allí a la que tú pariste y yo engendré, hecha pedaços $(C, 336)$.

Mas, si a ti plazerá, padre mío, mandar traer algún instrumento de cuerdas con que se sufra mi dolor o tañiendo o cantando, de manera que, aunque aquexe por una parte la fuerça de su accidente, mitigarlo han por otra los dulçes sones y alegre armonía $(C, 330-331)$. 
Y dentro de un mismo enunciado:

Mas como yo este oficio le hobiese mamado en la leche, quiero decir que con el gran maestro el ciego lo aprendí $[\ldots](L, 87)$.

2.2. Por contra, cuando el sustantivo de «no persona» está en plural no aparece les, sino los. Compárense los ejemplos que siguen:

[...] y apenas hubo entrado Preciosa, cuando el caballero del hábito vio el papel que traía en el seno, y llegándose a ella se le tomó $(G, 73)$.

Los niños con los juegos, [...] los viejos con mill especies de enfermedades pelean y estos papeles con todas las edades. La primera los borra y rompe, la segunda no los sabe bien leer $(C, 80)$.

2.3. Podría pensarse que el factor determinante para la selección le / lo en estos casos es, como señaló Rafael Lapesa ${ }^{4}$ para los orígenes del leísmo, el tipo de verbo del que dependen los pronombres átonos. Sin embargo, en el XVI parece que los usos leístas están perfectamente asentados, como demuestran las alternancias que se producen en la referencia a un mismo sustantivo con un mismo núcleo verbal:

Fueme tan bien en el oficio, que al cabo de cuatro años que lo usé, con poner en la ganancia buen recaudo, ahorré para me vestir muy honradamente de la ropa vieja $(L, 126-127)$.

Hame sucedido tan bien, yo $\underline{\text { le he }}$ usado tan fácilmente, que casi todas las cosas al oficio tocantes pasan por mi mano $(L, 130)$.

Corrobora este estado avanzado el leísmo de «no persona» con verbos que, ya desde el latín, eran eminentemente transitivos:

[...] todos mis trabajos y fatigas hasta entonces pasados fueron pagados con alcanzar lo que procuré, que fue un oficio real, viendo que no hay nadie que medre, sino los que $\underline{\text { le tienen }}(L, 128)$.

Por ello creo que la hipótesis de Lapesa, si bien explica las causas históricas del leísmo y sus fenómenos adyacentes, no resulta operativa para el leísmo no personal en la lengua del siglo Xvi.

\footnotetext{
${ }^{4}$ Rafael Lapesa, «Sobre los orígenes y evolución del leísmo, laísmo y loísmo», en Festschrift Walther von Wartburg zum 80. Geburtstag, I, Tübingen, Max Niemeyer, 1968, págs. 523-551.
} 
2.4. Ante el grueso de ejemplos estudiados, llama la atención el que la alternativa le / lo para hacer mención de masculinos no referidos a persona se presenta con un grupo bastante estable de sustantivos, lo cual conduce a plantear si en la elección del referente átono por los hablantes no tendrán algo que decir los valores de contenido del nombre que se desea sustituir.

El hecho es que en las obras este tipo de leísmo se da con los siguientes sustantivos. En La Celestina: abrigo, año, beneficio, bote, cavallo, corazón, cordón, cuydado, despediente ('despedida'), dicho, interesse, jarro, laúd, lugar, manto, mundo, nebli, nombre, pandero, pecho, pensamiento, plazer, ratón, remedio, sabor, secreto, temor, vientre, vívora ('macho'). En el Lazarillo: arcaz, bodigo, bonete, caso, colchón, cuchillo, jarro, oficio, real. $\mathrm{Y}$ en La gitanilla: acogimiento, adulterio, amor, ánimo, bayo, cargo, caso, cofrecico, cuarto, dedal, doblón, escudo, hábito, hoyo, hurto, lunar, nombre, oficio, papel, parto, peligro, rancho, real, romance, rostro, secreto, soneto.

A primera vista la enorme heterogeneidad de los sustantivos dificulta una clasificación. Sin embargo, por su recurrencia sí se pueden delimitar ciertos espacios léxicos que parecen más propicios a la sustitución por le. La nota común a todos - sean nombres concretos o abstractos- es que los susceptibles de referencia leísta parecen ser siempre contables.

\subsubsection{Sustantivos concretos y contables}

El campo semántico del dinero (cuarto, doblón, escudo, real): estos nombres siempre ofrecen la alternancia $l e / l o$, con total predominio de le en La gitanilla, donde su uso es mayor:

[...] un día, no sé por cuál dicha o ventura, en el pobre poder de mi amo entró un real, con el cual él vino a casa tan ufano como si tuviera el tesoro de Venecia, y con gesto muy alegre y risueño me lo dio [...] Tomo mi real y jarro y, a los pies dándoles priesa, comienzo a subir mi calle, encaminando mis pasos para la plaza [...] echando mi cuenta en lo que le emplearía, que fuese mejor y más provechosamente gastado ( $L, 95-96)$.

Finalmente, el doblón de dos caras se le dieron a Preciosa, y ella dijo a sus compañeras que le trocaría y repartiría con ellas hidalgamente. $(G, 97)$.

Pidió un cuarto a sus criadas, y ninguna le tuvo, ni la señora vecina tampoco $(G, 78)$.

Las referencias a animales (bayo, cavallo, nebli, ratón, vívora) también son contextos frecuentes de leísmo no personal:

Señor, porque perderse el otro día el neblí fue causa de tu entrada en la huerta de Melibea a le buscar $(C, 134-135)$. 
Del mismo modo sucede con los objetos o cosas, preferiblemente de pequeño tamaño (arcaz, bodigo, bonete, bote, cofrecico, colchón, cordón, cuchillo, dedal, jarro, laúd, manto, pandero, papel):

Usaba poner cabe sí un jarrillo de vino, cuando comíamos, y yo muy de presto le asía y daba un par de besos callados y tornábale a su lugar $(L, 30-31)$.

Levantéme muy quedito y, habiendo en el día pensado lo que había de hacer y dejado un cuchillo viejo que por allí andaba en parte do le hallase, voyme al triste arcaz, y por do había mirado tener menos defensa le acometí con el cuchillo, que a manera de barreno dél usé $(L, 62)$.

[...] tomo entre las manos y dientes un bodigo, y en dos credos le hice invisible $(L, 56)$.

Así también con ciertas partes del cuerpo (corazón, hoyo, lunar, pecho, rostro, vientre):

¡Ay, qué hoyo! En este hoyo han de tropezar cuantos ojos le miraren $(G, 77)$.

Un lunar tienes, iqué lindo! / [...] Más de dos ciegos por verle / dieran más de cuatro blancas $(G, 80)$.

$\mathrm{Y}$ con otros sustantivos concretos de referencia más «intangible», pero igualmente contable: año, cargo, caso, dicho, hurto, lugar, mundo, nombre, oficio, secreto, etc.

ALISA. [...] Dime su nombre si le sabes.

LUCRECIA. ¿Si $l e$ sé, señora? No ay niño ni viejo en toda la cibdad que no le sepa; ¿avíale yo de ignorar? $(C, 152)$.

Y pues Vuestra Merced escribe se le escriba y relate el caso muy por extenso, parescióme no tomalle por el medio, sino del principio $(L, 10-11)$.

\subsubsection{Sustantivos abstractos, tomados como contables}

Conceptos como adulterio, amor, ánimo, beneficio, cuydado, dolor, pensamiento, plazer, temor, etc. se sienten como discontinuos si se acompañan de ciertos adjetivos (demostrativos, posesivos, cuantificadores, calificativos) que los individualizan o determinan, convirtiéndolos en referencia concreta: 
¡O quántos días antes de agora passados me fue venido esse pensamiento a mi coraçón, y por impossible le rechaçava de mi memoria $(C, 261)$.

Y por que el incogitado dolor te dé más pena, todo junto sin pensarle, [...] vez allí a la que tú pariste y yo engendré, hecha pedaços. $(C, 336)$.

Entre nosotros, aunque hay muchos incestos, no hay ningún adulterio; y cuando le hay en la mujer propia, o alguna bellaquería en la amiga, no vamos a la justicia a pedir castigo $(G, 101)$.

[...] a nuestro ánimo no le tuercen cordeles, ni le menoscaban garruchas, ni $l e$ ahogan tocas, ni $l e$ doman potros. $(G, 101-102)$.

Otro procedimiento para la disolución del rasgo «continuo» en los nombres abstractos puede ser, como ocurre aquí con cuydado, la personificación:

Vença plazer al cuydado / y no le vea, / pues te ha hecho su privado / Melibea $(C, 276)$.

2.5. Frente a lo anterior, para los sustantivos continuos de género masculino se utiliza siempre lo. En este sentido son muy claros dos ejemplos en los que, dentro del mismo contexto, se contraponen un nombre contable (jarro $\rightarrow$ le) y otro no contable (vino $\rightarrow l o$ ):

[Mis necesidades] me las paso sin que las sienta la tierra, comiendo quando puedo, beviendo quando lo tengo. Que con mi pobreza jamás me faltó, a Dios gracias, una blanca para pan y un quarto para vino, después que embiudé, que antes no tenía yo cuydado de lo buscar [...] Agora, como todo cuelga de mí, en un jarrillo mal pegado me lo traen, que no cabe dos açumbres. Seys vezes al día tengo de salir, por mi pecado, con mis canas a cuestas, a le henchir a la taverna $(C, 159)$.

Cuando el pobreto iba a beber, no hallaba nada, espantábase, maldecíase, daba al diablo el jarro y el vino, no sabiendo qué podía ser.

- No diréis, tío, que os lo bebo yo - decía-, pues no le quitáis de la mano $(L, 32)$.

2.6. Así pues, en coexistencia con los rasgos «masculino», «singular», «no persona» parece que el leísmo alcanza sólo a los nombres comunes contables, pero no a los continuos. Este hecho corrobora una vez más el rendimiento funcional de la oposición «continuo» / «discontinuo», que resulta 
operativa en múltiples aspectos gramaticales ${ }^{5}$. El más destacado de los cuales es, sin duda, el neutro de materia, fenómeno con el que se vincula de manera estrecha la evolución del leísmo de «no persona», según intentaré demostrar.

\section{EL NEUTRO DE MATERIA Y SU RELACIÓN CON EL LEÍSMO}

3.1. Puesto de relieve primeramente por Ramón Menéndez Pidal, quien habló de una «discordancia» entre nombre y adjetivo pospuesto (lleche preso) posible en Asturias «especialmente con algunos sustantivos de materia cuando van en singular indicando la materia en general y no ninguna parte de ella ni ningún objeto hecho con ella» ${ }^{6}$, la etiqueta neutro de materia, que consagró Dámaso Alonso en un estudio clásico ${ }^{7}$, no alude a un género gramatical, sino a un tipo específico de concordancia que establecen los sustantivos (masculinos y femeninos) continuos o no contables.

3.2. En las áreas geográficas donde el fenómeno se conserva en grado más regular ${ }^{8}$, el neutro de materia se manifiesta con el artículo y con los pronombres (tónicos y átonos) y adjetivos (calificativos $\mathrm{y}$, a veces, también determinativos) que poseen variación triple de género, así como con el partitivo asturiano ${ }^{9}$. Estas unidades adoptan su forma «neutra» ${ }^{10}$ cuando acompañan (como adyacente pospuesto, pero no si se le anteponen), reproducen o se refieren a un sustantivo continuo. Sin embargo, ese «neutro» no es tal,

\footnotetext{
${ }^{5}$ Por ejemplo, en la posibilidad del nombre de combinarse con ciertos morfemas («artículo», «plural»), con los cuantificadores, con ciertos sustantivos (mitad, medio), etc.; requisitos estos que influyen decisivamente en el funcionamiento sintáctico de los sustantivos no contables. Véase Emilio Alarcos Llorach, Estudios de gramática funcional del español, Madrid, Gredos, 3.a edic., 1980, págs. 275-286; Ignacio Bosque, «Clases de nombres comunes», en Serta Philologica F. Lázaro Carreter, I, Madrid, Cátedra, 1983, págs. 75-88; José Antonio Martínez, Funciones, categorías y transposición, Madrid, Istmo, 1994, págs. 104-114.

${ }^{6}$ Ramón Menéndez Pidal, El dialecto leonés, Oviedo, Instituto de Estudios Asturianos, 1962, págs. 109-110.

7 Dámaso Alonso, «Metafonía, neutro de materia y colonización suditaliana en la Península Hispánica», en Obras completas, I, Madrid, Gredos, 1972, págs. 147-213.

${ }^{8}$ Las comarcas del centro de Asturias y los valles pasiegos de Cantabria, esto es, la llamada «zona A» del territorio neutro, según F. García González, «El neutro de materia», págs. 95-97.

9 Acerca del partitivo puede verse Alonso Zamora Vicente, Dialectología española, Madrid, Gredos, 2. ${ }^{\text {a }}$ edic., 1967, pág. 205.

${ }^{10} \mathrm{El}$ asturiano, frente al castellano, conserva la triple distinción de género en los adjetivos, pero no en los sustantivos comunes, que sólo pueden ser masculinos o femeninos. Por tanto, la aparente forma «neutra» en un adjetivo adyacente de un nombre no puede tomarse por marca de género (ya que el género lo impone el sustantivo), sino de otra cosa. Véase Jesús Neira Martínez, «La oposición continuo / discontinuo en las hablas asturianas», en Estudios ofrecidos a Emilio Alarcos Llorach, III, Oviedo, Universidad de Oviedo, 1978, págs. 255-279.
} 
pues no funciona como morfema repetidor del género del nombre. Su única función consiste en indicar que dentro de los valores de contenido del sustantivo se encuentra el de «no contable». Contra la opinión de D. Alonso, Jesús Neira ${ }^{11}$ comprobó que el neutro de materia es un morfema que reclasifica sintácticamente al sustantivo —que no deja de ser masculino o femenino desde el punto de vista léxico- como «no contable». Lo que sucede es que la marca de «continuidad» se superpone a la de «género».

3.3. El neutro de materia pervive con fuerza en las mencionadas áreas de Asturias y Santander, pero no se restringe a ellas, sino que se detecta, al menos, en toda la franja centro-norte peninsular ${ }^{12}$. Tampoco es ajeno a la lengua española, ya que, como ha mostrado F. García González ${ }^{13}$, se encuentran probables ejemplos de neutro de materia en textos castellanos, desde los más antiguos (Cid, Vida de Santa María Egipciaca, Libro de Buen Amor) hasta Delibes, pasando por Santa Teresa o Cervantes.

3.4. Con tales premisas, puede afirmarse que se trata (y se trató) de un fenómeno lo suficientemente amplio como para haber influido de forma significativa en el desarrollo de otros muy cercanos a él. En concreto, en el leísmo de «no persona». La proximidad gramatical entre neutro y leísmo, en principio, se muestra en tres aspectos.

3.4.1. El neutro de materia, como el leísmo no personal, se da en solidaridad con el número «singular» debido a su propia naturaleza, puesto que los sustantivos susceptibles de «pluralidad» están tomados como contables aunque en singular puedan ser continuos ${ }^{14}$. En palabras de J. Neira, «el sustantivo de materia continua es por esencia invariable. Si admite modificaciones de número o de género es que se ha pasado a la esfera de la discontinuidad material con su comportamiento característico» ${ }^{15}$.

\footnotetext{
11 J. Neira Martínez, art. cit., págs. 261-263.

12 F. García González, «/le (lu), la, lo (lu)/ en el Centro-Norte...», ha estudiado la extensión del fenómeno en Asturias, Santander, Vizcaya, Álava, Burgos, Palencia, León y Valladolid. En el mismo sentido, F. Klein-Andreu, «Distintos sistemas de empleo de le, la, lo...», detecta neutro de materia en zonas rurales de Valladolid.

${ }^{13}$ F. García González, «Algo más sobre el neutro de materia», págs. 35-36.

${ }^{14} \mathrm{El}$ número plural «representa una suerte de 'cuantificación' mínima», según J. A. Martínez, op. cit., pág. 107. Téngase en cuenta además que, aparte del paso «singular» $\rightarrow$ «plural», los sustantivos continuos se recategorizan como contables (y viceversa) de múltiples maneras (§ 2.4.2.), ya que la oposición «contable» / «incontable» es, más que nada, contextual. Así, existe un elevado número de nombres que pueden tener una acepción «continua» y otra «discontinua» dependiendo del entorno lingǘstico que los rodee (la belleza $\rightarrow$ una belleza). Véase también el artículo de I. Bosque citado en la nota 5.

15 J. Neira Martínez, art. cit., pág. 272.
} 
3.4.2. Otra conexión entre ambos accidentes la encontramos en el hecho de que el área geográfica del neutro de materia y la del leísmo más evolucionado son bastante semejantes (zona centro-norte peninsular). En el sur de España e Hispanoamérica, en cambio, no se conoce ni neutro de materia ni leísmo de «no persona».

3.4.3. Si prescindimos de las restantes manifestaciones del neutro de materia y observamos sólo su repercusión en los referentes átonos de $\mathrm{CD}$, veremos que existe un punto más de confluencia entre éste y el leísmo no personal: en ambos casos la forma lo es la utilizada para reproducir nombres no contables.

3.4.4. Ahora bien, también hay discordancias entre los dos fenómenos. La más evidente es que en el neutro de materia lo alude tanto a masculinos como a femeninos, mientras que en nuestros datos, en el marco de la lengua española, los ejemplos femeninos son muy escasos y sólo aparecen en el texto más antiguo (La Celestina) ${ }^{16}$. La razón es que el castellano sustituye los sustantivos femeninos (sean contables o no contables) mediante el referente $l a$. Por ello, no puede hablarse de la pervivencia del neutro de materia en el siglo XVI, aunque creo que tampoco se trata de un hecho totalmente erradicado en el castellano de la época.

\section{UNA HIPÓTESIS SOBRE EL DESARROLLO HISTÓRICO DEL LEÍSMO}

4.1. En el panorama lingüístico del siglo XVI, pues, lo primero que queda claro es que el leísmo se encuentra extendido prácticamente a la totalidad de CDs masculinos de «persona», pero sólo en singular. Esto demuestra (y se debe a) que uno de los factores primigenios que han contribuido a la sustitución de lo por le es la conveniencia de oponer fónicamente tres unidades ya enfrentadas morfológicamente, esto es, la conveniencia de diferenciar el género masculino $(l e)$ del neutro $(l o)$ en el $\mathrm{CD}$, aun a pesar del sincretismo de «caso» o «función». Ciertamente, allí donde no hay neutro no hay leísmo; de ahí que el leísmo plural sea muy poco relevante, pues en plural no existe una forma neutra a la que oponer la masculina.

Por tanto, la aparición del leísmo se debe a una necesidad gramatical: marcar en la expresión una oposición de contenido (la de géneros) que ya

\footnotetext{
${ }^{16}$ Aunque son bastante dudosos, podrían mencionarse los que cito a continuación: «[...] que aun la mesma vida de los hombres, si bien lo miramos, desde la primera edad hasta que blanquean las canas, es batalla» $(C, 80)$; «Pero como todo don o dádiva se juzgue grande o chica respecto del que $l o$ da, no quiero traer a consequencia mi poco merecer» $(C, 251)$.
} 
existía en la lengua, a costa de deshacer otra (la de casos). El referente singular del CI (le) pasó a serlo también del CD a través de un proceso sintáctico, explicado hace tiempo por Rafael Lapesa ${ }^{17}$, que consistió básicamente en la conservación del dativo con un grupo de verbos que en latín regían este caso, y la extensión del mismo régimen a otros verbos romances sin precedentes latinos de dativo. El campo de acción fue, en un primer momento, el CD de persona; después se amplió a la noción de «no persona», aunque con menor desarrollo y casi siempre en singular.

4.2. De manera simultánea debió de entrar en juego un segundo factor, relacionado con la consciencia de que la función propia de le $(\mathrm{el} \mathrm{CI})$ tenía un contenido predominantemente de «persona». La consecuencia fue que la forma le se especializara, también en el $\mathrm{CD}$, para la reproducción de sintagmas masculinos con valor «personal». Ya lo había visto Salvador Fernández Ramírez ${ }^{18}$, que añade como causa adicional la similitud de le con los átonos me y te:

Al mismo tiempo que se intentaba la regularización del paradigma masculino y la diferenciación genérica, se produjo un efecto secundario, suscitado por el hecho de que el le dativo, que venía a ser el foco de atracción, es un caso eminentemente personal, y al mismo tiempo por el hecho de que las formas $m e$, te, a cuyo patrón se ajustaba también el nuevo acusativo masculino, realizan mención exclusiva de persona. [...] Fue así intentándose desde entonces reducir la función de le acusativo a la mención de persona, y es curioso que este efecto, secundario al parecer, fue el de mayor alcance, pues el índice de frecuencia de este uso ha crecido considerablemente desde el siglo XVI hasta nuestros días.

Este empleo de le por lo en el CD masculino singular de «persona» constituye lo que cabría llamar leísmo original (el leísmo «justificado» gramaticalmente), a partir del cual surgirán los demás fenómenos conexos. M. ${ }^{\mathrm{a}}$ T. Echenique señala la Fazienda de Ultramar como momento clave para el nacimiento del leísmo personal. Posteriormente, el descenso en el empleo de las formas apocopadas favorecerá la restitución del referente etimológico $l o$, pero, como ella escribe, «el camino a la vacilación está ya abierto» ${ }^{19}$.

\footnotetext{
${ }^{17}$ R. Lapesa, art. cit. Los contextos sintácticos más propensos a la sustitución de dativo por acusativo habían sido comentados por Rufino José Cuervo, «Los casos enclíticos y proclíticos del pronombre de tercera persona en castellano», Romania, XXIV, 1895, págs. 95-113 y 219-263; reeditado en sus Obras, III, Bogotá, Instituto Caro y Cuervo, 2. a edic., 1987, págs. 167-239.

${ }^{18}$ Cf. Salvador Fernández Ramírez, «Un proceso lingüístico en marcha», en Gramática española. 3.2. El pronombre, Madrid, Arco/Libros, 1987, págs. 395-396.

${ }_{19}$ María Teresa Echenique Elizondo, «El sistema referencial en español antiguo: leísmo, laísmo y loísmo", Revista de Filología Española, LXI, 1981, págs. 113-157 (para la cita, págs. 154-155). Esta autora ha comprobado que en la Fazienda de Ultramar existe vacilación
} 
4.3. El apunte anterior de S. Fernández Ramírez puede completarse con la consideración de un fenómeno coadyuvante del leísmo original y, a la vez, muy probable motivador del leísmo no personal, a saber: la omnipresencia de la preposición $a$ en la función de $\mathrm{CI}$, es decir, la consciencia de que le sustituía siempre a sintagmas encabezados por dicha preposición. Si bien el mismo Fernández Ramírez había puesto de manifiesto la relación entre la presencia de $a$ (como marca de «persona» en el CD) y la no extensión de le a todo el acusativo de $\cos ^{20}$, sin embargo opino que lo verdaderamente relevante fue que ese índice funcional no sólo era propio del $\mathrm{CI}$, sino que se había extendido, ya desde los siglos XIII-XIV, a los CDs de referente determinado ${ }^{21}$. Entre estos se incluirían; por supuesto, los de contenido personal (primer campo de acción del leísmo), pero también otros con referencia igualmente concreta, aunque de contenido no personal. Por tanto, el pronombre átono $l e$, originario reproductor de sintagmas con $a$, habría pasado

lo / le con verbos que en latín no pedían el dativo, mientras que en en el manuscrito I-I-6 de la Biblia Escurialense ya se registra absoluta mayoría de le. A comienzos de la segunda mitad del siglo XIII, por tanto, el leísmo masculino singular de persona se ha extendido a la mayor parte de los verbos, sin que responda a ningún factor de etimología. Por su parte, María del Carmen Sanchís Calvo, «Sobre el leísmo y la apócope del pronombre de tercera persona singular objeto directo", en Actas del II Congreso Internacional de Historia de la Lengua Española, I, Madrid, Pabellón de España s.a., 1992, págs. 805-812, también fecha las primeras muestras de leísmo a principios del siglo XIII y constata que «es predominante ya antes de 1250 y aumenta con posterioridad hasta hacerse casi exclusivo», llegando a rozar el $100 \%$ en fragmentos de la Primera Crónica General (pág. 807).

${ }^{20}$ «La resistencia a emplear el $l e$ en todas las funciones de acusativo, representada por el leísmo moderado, no tiene otra explicación, ya lo hemos dicho, que la repugnancia instintiva a emplear con significación de cosa una forma [la preposicional con a] que se sentía inseparable de la significación de persona» (S. Fernández Ramírez, art. cit., pág. 397).

${ }^{21}$ Como ha estudiado José María García Martín, «Objetos directos preposicionales no personales en la prosa castellana de los siglos XIII y XIV», en Actas del I Congreso Internacional de Historia de la Lengua Española, I, Madrid, Arco/Libros, 1988, págs. 363-375. García Martín concluye que en esos siglos «la preposición ha alcanzado a los sustantivos o asimilados que ostentan referencia no determinada, pero sólo está consolidada con los referenciales determinados y con los especificos. Dada la similitud de funcionamiento con los objetos directos personales a este respecto, todas las subclases nominales muestran un comportamiento más o menos similar, lo que lleva a pensar que la a funciona como indicadora de la función 'objeto directo'» (pág. 373, subrayado mío). Las formas de determinación que señala (actualización por artículo, posesivos o demostrativos) son análogas a las expuestas en $\S 2.4 .2$. para el paso de "continuo» a "contable», con la subsiguiente repercusión en el uso de los referentes átonos. De esta manera queda suficientemente probado el estrecho vínculo que existe entre la preposición en el CD (más importante como marca de «determinación» o «discontinuidad» que de «animación» o «personalidad») y la sustitución de esos sintagmas mediante un pronombre átono: $l e$ para referentes determinados o contables, $l o$ para referentes no contables (empleo que se mantiene por la influencia del neutro de materia, como se verá en $\S \S$ 4.7. y 4.8.). Según creo, el parámetro «contable» / «no contable» tuvo una actuación mucho más decisiva que la oposición «persona» / «cosa» en la evolución de los sintagmas en función de $\mathrm{CD}$, tanto en lo referente al uso de la preposición $a$ como a su reproducción mediante le / lo. 
a referir, sin otro tipo de distinciones, también a los CDs preposicionales (personales o no, pero con el rasgo "t determinado»).

Me parece éste un elemento de especial relevancia, ya que significaría que en el avance del leísmo hacia la «no persona» habría intervenido un factor (la «determinación» del sintagma en función de CD) que viene a ser redundante con otro (la «discontinuidad» de los sustantivos reproducidos con le) de importancia sobresaliente a la hora de explicar la alternancia entre le y lo en los CDs masculinos no personales.

4.4. Carlos Folgar ${ }^{22}$ también ha resaltado la funcionalidad de los parámetros «masculino» / «neutro» por un lado, y «persona» / «no persona» ${ }^{23}$ por otro. Su confluencia, según este autor, explica el origen de los leísmos de persona y de cosa. La separación que con posterioridad sufrieron ambos parámetros justificaría la división dialectal del español de hoy. Así, en el territorio peninsular donde el castellano es lengua autóctona habría triunfado el parámetro «masculino» / «neutro», imponiéndose el leísmo masculino (tanto de persona como de cosa). En cambio, donde el castellano es lengua importada habría tenido más suerte el «efecto secundario» encaminado a distinguir "persona» / "cosa», de ahí que el uso etimológico de lo alterne con usos leístas para la mención de "persona» en el CD masculino singular. Los sintagmas masculinos de «no persona», por tanto, pudieron asimilarse al nuevo referente (le) o quedarse en el etimológico (lo), según la zona geográfica y el parámetro preponderante.

Sin embargo, estas razones no parecen del todo convincentes, puesto que no justifican por qué en las áreas leístas los sustantivos de «no persona» se reproducen a veces con $l o$ y a veces con le. ¿Se deja a la libre elección de cada hablante? ¿No es posible una explicación fundada lingüísticamente?

4.5. Ha quedado claro que el leísmo masculino singular surge por la presión que ejerce el parámetro «masculino» / «femenino» / «neutro», y en especial la oposición «masculino» / «neutro», reclamando expresiones diferenciadas para los distintos contenidos. Ese leísmo se aplica en un principio a los sustantivos de «persona», ya que la forma $l e$, originaria del $\mathrm{CI}$,

${ }^{22}$ Cf. Carlos Folgar, Diacronía de los objetos directo e indirecto (del latín al castellano medieval), Anexo 37 de Verba, Universidad de Santiago de Compostela, 1993, págs. 154-165.

${ }^{23} \mathrm{La}$ relevancia de tales oposiciones, sobre todo de la distinción entre "persona» / "cosa», ya la había observado Rafael Lapesa, «Evolución sintáctica y forma lingüística interior en español», en Actas del XI Congreso Internacional de Lingüistica y Filología Románicas, ed. A. Quilis, vol. I, Madrid, CSIC (Revista de Filología Española, Anejo LXXXVI), 1968, págs. 131-150. De todos modos, como he dicho antes (nota 21), la pertinencia del parámetro «persona» / «no persona» se ha sobrevalorado en las explicaciones tradicionales del leísmo. 
poseía el rasgo «+ personal» en la mayoría de usos (leísmo original). Ello hizo que el parámetro «persona» / «no persona» se superpusiera al primerizo «masculino» / «neutro», dando lugar a una cuádruple oposición: «masculino personal» (le ) / «masculino no personal» (lo ) / «femenino» (la) / «neutro» $(l o)$.

Pero el estado de lengua que se encuentra en el XVI no es explicable sólo con tales consideraciones. Si bien en ellas encuentra acomodo el leísmo singular de «persona», propagado prácticamente al $100 \%$ de los usos, el de «no persona» reclama una justificación de la alternancia entre $l e$ y $l o$, porque si sólo tuviéramos en cuenta los dos parámetros hasta ahora señalados sería lógico suponer que, en las zonas leístas, el átono le también ocupó (y ocuparía hoy) el $100 \%$ de los ejemplos para el masculino no personal, lo cual es falso incluso en una época altamente leísta como el Siglo de Oro.

4.6. Para aclarar este punto, que constituye el paso final y decisivo en el desarrollo del leísmo, es conveniente repasar de nuevo las cifras. Tomados con la debida cautela (por las posibles adiciones, supresiones y modificaciones que hayan sufrido), puede afirmarse que los textos que he analizado corresponden básicamente al habla centropeninsular, leísta en el sentido más amplio.

Los datos reflejan con claridad que el leísmo original domina el siglo desde sus inicios, se halla completamente asentado en el uso habitual. Convive con lo en La Celestina y el Lazarillo y llega a ser la forma exclusiva del CD masculino singular de "persona» en La gitanilla. Según lo visto en $\S 2.3$., las causas originarias del leísmo han pasado a la historia, el habla estándar ya no distingue unos verbos con los que el CD le es «correcto» y otros en los que el átono de $\mathrm{CD}$ «debe ser» lo. Además de su función propia (CI), le ocupa la práctica totalidad del $\mathrm{CD}$ masculino singular cuando hace mención de «persona».

La situación resulta muy propicia para el leísmo de «no persona». Y lo es porque, en su origen, ambos tipos de leísmo son dos caras de la misma moneda, lo que se comprueba en el hecho de que ninguno de los dos se encuentre habitualmente en plural: si de leísmo original hay pocos casos, los ejemplos de les referido a la «no persona» son nulos. La causa es que, como se indicó en $\S$ 4.1., los leísmos nacen para dar expresión fónica a una oposición morfológica («masculino» / «femenino» / «neutro»), motivada por la existencia de un «neutro». Pero donde no hay neutro (así sucede en el plural) no es necesario el leísmo. En el mismo sentido, viene a confirmar la inseparabilidad de ambas clases de leísmo la apreciación de que cuanto más intenso fue, en castellano medieval, el leísmo de «persona», más intenso fue también el de «cosa» (que no alcanzó más que a textos donde el 
leísmo personal era muy abundante $)^{24}$. Significa esto que el segundo es, desde siempre, una consecuencia lógica del primero.

Ahora bien, es preciso tener en cuenta que, en una época como la que aquí se estudia, en la que el leísmo de «persona» ya está generalizado, el alto grado de leísmo original no es por fuerza directamente proporcional al grado de leísmo de «no persona». En todos los textos el leísmo original ocupa entre el 90 y el $100 \%$ de los usos, mientras que el leísmo de «no persona» no alcanza porcentajes realmente destacados hasta la lengua cervantina (dos tercios del total de ejemplos en La gitanilla).

Según parece, el campo leísta se va ampliando de forma progresiva hacia la «no persona», pero esa invasión se produce a través del tiempo, diacrónicamente, es decir, como consecuencia de la total consagración del leísmo original. Esta consagración ya se ha producido en el XVI; la del leísmo no personal, en cambio, es posterior y nunca llega a ser absoluta, esto es, a ocupar el $100 \%$ de los ejemplos. En otras palabras, ha sido necesaria la general expansión del leísmo en el territorio "personal» para que le penetrara de manera consistente en el dominio de la «no persona».

4.7. Con el precedente del leísmo personal cabe suponer que, de no haber encontrado resistencia a su paso, la invasión leísta habría acabado por ocupar en un breve lapso cronológico (si no lo hubiera conseguido ya en el siglo $\mathrm{xVI}$ ) el $100 \%$ de las referencias a sustantivos no personales, al menos en las zonas donde primó la distinción «masculino» / «neutro». Así pues, es preciso preguntarse la razón de que no haya sucedido así, es decir, por qué los ejemplos de le que cubren la noción de «no persona» alternan con otros donde se emplea $l o$, y también si ese leísmo responde a algún criterio gramatical o es una simple extensión analógica del leísmo original.

Descartadas para el estado de lengua del siglo XvI las explicaciones de R. Lapesa, he intentado aproximarme a los pocos rasgos que presentan en común los casos de leísmo no personal, comprobando que los sustantivos reproducidos por le poseen una característica común en cuanto a la forma ${ }^{25}$ del contenido (son contables), que se opone a otra que reúnen los reproducidos por $l o$ (son continuos).

Por ello, podría decirse que, tras la actuación de los dos primeros parámetros, habría entrado en funcionamiento la pertinencia de la oposición

${ }^{24}$ Cf. M. ${ }^{\text {a }}$ T. Echenique, art. cit., pág. 155, y M. ${ }^{\text {a }}$ C. Sanchís Calvo, art. cit., pág. 811.

${ }^{25} \mathrm{La}$ oposición «continuo» / "discontinuo» es hoy, sin duda, pertinente y funcional en castellano, y no sólo en este caso (repásese la nota 5). Desde el punto de vista diacrónico, también parece haber influido en el desarrollo de ciertos fenómenos gramaticales, como la creación del artículo romance. Véase al respecto R. Lapesa, «Evolución sintáctica y forma lingüística interior...», pág. 142. 
«continuo» / «discontinuo», dando como resultado la sustitución por lo de los sustantivos no contables (todos ellos son de «no persona»). Si bien los femeninos han de mencionarse siempre con la, como manda el uso etimológico castellano, ¿por qué no pensar que un resto del neutro de materia, precisamente aquel que no producía ningún tipo de discordancia con el paradigma etimológico castellano ${ }^{26}$, se haya mantenido latente en los hablantes, evitando la total extensión de le en el campo del masculino? Del mismo modo que hoy, dependiendo de la zona, varían los niveles de intensidad (es decir, de concordancia entre el sustantivo y el adjetivo pospuesto) del neutro de materia ${ }^{27}$, el castellano del XVI pudo conservar el neutro como resto único en los referentes de CD masculino no personal. Los ejemplos estudiados parecen ratificarlo: el neutro de materia habría actuado a modo de sustrato, como freno al avance del leísmo masculino en el campo de la «no persona». El hecho de que los sustantivos continuos se reprodujeran siempre con lo pudo ser decisivo para que los hablantes no asimilaran todas las referencias no personales (ni siquiera todas las contables) al pronombre le.

Considero, por tanto, que el influjo de la oposición «contable» / «no contable» es desde el punto de vista diacrónico el tercer parámetro que influye sobre el uso de los referentes de CD. Como explica F. Klein-Andreu ${ }^{28}$, su consolidación fue posible por el hecho de que entes contables se designaran previamente con formas específicas, como sucedía con los femeninos (la) y los masculinos de persona (le):

Así, al iniciarse la distinción de limitación, mediante el uso de lo para entes continuos, el que existiera ya alguna asociación entre le y algunos entes masculinos, normalmente individualizados, no podía más que facilitar la asociación de le con el significado «ente limitado masculino» en general.

Tras el originario «masculino» / «neutro» y el secundario «persona» / «no persona», el parámetro «contable» / «no contable» viene a matizar el inmediatamente anterior. Podría decirse que este tercero se incluye en el segundo, y el segundo en el primero, como cajas chinas. $\mathrm{Y}$ así, tendríamos que la cuádruple oposición formada de la fusión de los dos primeros parámetros (§ 4.5.) se convierte ahora en quíntuple, quedando como sigue: «masculino personal» $(l e) /$ «masculino no personal contable» $(l e \sim l o) /$ «masculino no personal no contable» $(l o) /$ «femenino» $(l a) /$ «neutro» $(l o)$.

\footnotetext{
${ }^{26}$ Esto es, el neutro para el masculino singular: frente a el agua bebilo, incorrecto en castellano, los hablantes no sentirían como discordante la expresión el vino bebilo.

${ }_{27}$ Véase la división en tres zonas que realiza F. García González, «El neutro de materia», págs. 94-99.

${ }_{28}$ F. Klein-Andreu, «Distintos sistemas de empleo de le, la, lo...», pág. 349.
} 
4.8. De esta manera se alcanza el paradigma que encontramos en la época más avanzada de leísmo (finales del XVI-siglo XVII). En él se aprecian dos sincretismos:

a) «masculino personal» $=$ «masculino no personal contable» ${ }^{29}, \mathrm{y}$

b) «masculino no personal no contable» = «neutro», que significan la superposición del parámetro «contable» / «no contable» sobre el parámetro «persona» / «no persona». Esta distinción ha quedado casi del todo anulada por aquella, de modo que el sistema tiende a diferenciar sustantivos continuos (lo) y discontinuos (le), dado que los de «persona» son todos contables.

Por otra parte, los sintagmas o grupos sintagmáticos de género neutro tienen el mismo referente que los masculinos no contables. Pero ello no implica una gran problemática, ya que, si el neutro de materia se conservó como influencia sustratística en el único campo donde no discordaba con el paradigma castellano (el masculino singular no personal), el pronombre lo habría neutralizado el valor del neutro de materia y el suyo propio, esto es, funcionaría como marca de «continuidad», a la vez que mantendría su valor genérico («neutro», en oposición a «masculino» y «femenino» ${ }^{30}$ ). La unidad resultante de esa neutralización no resultaría extraña, puesto que coincidía con la forma etimológica asignada tanto al masculino de cosa como al neutro (lo).

4.9. Por tanto, en la zona centro-norte de la Península, donde el leísmo tuvo (y tiene) más intensidad, una reducida pervivencia del neutro de materia pudo constituir el fenómeno decisivo para la distinción parcial en la reproducción de los sustantivos no personales mediante un pronombre átono. Se evitó así la total penetración del leísmo en el masculino singular, que probablemente habría tenido lugar de haberse consagrado sin interferencias el parámetro «masculino» / «neutro». En mi opinión, pues, adquiere validez la tesis de F. Klein-Andreu ${ }^{31}$ respecto a la adopción, aunque restringida, del neutro de materia por el castellano.

\footnotetext{
29 Este es un sincretismo sólo parcial, pues los sustantivos no personales contables tienen la posibilidad de ser sustituidos tanto por le como por $l o$.

30 Sobre la cuestión del género «neutro» pueden verse: Sebastián Mariner, «Situación del neutro románico en la oposición genérica», Revista Española de Lingüística, 3, 1, 1973, págs. 23-38; José Manuel González Calvo, «El género, ¿una categoría morfológica?», Anuario de Estudios Filológicos, II, 1979, págs. 51-73; José Antonio Martínez, Propuesta de gramática funcional, Madrid, Istmo, 1994, págs. 153-194.

${ }^{31}$ En «Distintos sistemas de empleo de le, la, lo...» F. Klein-Andreu, a partir de los datos obtenidos de varias encuestas dialectales en la provincia de Valladolid, postula la asimilación del neutro de materia por el castellano en beneficio del desarrollo de un sistema «referencial», por encima del «casual». También F. García González, «/le (lu), la, lo (lu)/ en el Centro-Norte...», págs. 352-353, había observado la pertinencia del rasgo «contable» / «no contable» en el uso de los referentes átonos de CD en español, especialmente en cuanto al leísmo de cosa.
} 
Finalmente, creo justo decir que la conclusión a la que he llegado no hace sino ampliar los márgenes (cronológicos y espaciales) de uso del paradigma IV (le para masculinos contables, $l a$ para femeninos, lo para masculinos no contables y neutros) que F. García González ${ }^{32}$ señaló en el habla santanderina actual. Los ejemplos analizados ratifican que ese esquema, presente hoy en el área cántabra, está muy próximo al que se utilizaba en la lengua castellana del siglo XVI y se debe a igual causa (el influjo del neutro de materia vecino). La única diferencia es que en el español del XVI los sustantivos masculinos no personales en función de $\mathrm{CD}$ aún presentan alternancia en sus referentes átonos, pudiendo ser sustituidos tanto por le como por $l o$ : mientras que los continuos siempre exigen $l o$, los contables se decantan preferentemente por $l e$, aunque también (en menor medida) son sustituidos por $l o$.

${ }^{32}$ F. García González, «El leísmo en Santander», pág. 94. Desde un punto de vista sincrónico y dialectal, en este artículo de 1978 se apuntaba ya la relevancia de la oposición «contable» / «no contable» propia del asturleonés en la explicación de otros fenómenos colindantes $\mathrm{y}$, en especial, en el uso de los pronombres átonos de $\mathrm{CD}$. 